\title{
Quality of Lipid Fractions in Deep-Fried Foods from Street Vendors in Chile
}

\author{
Marcos Flores $\mathbb{D}^{1},{ }^{1}$ Lucia Meyer, ${ }^{2}$ Sandra Orellana, ${ }^{1}$ Carolina Saravia, ${ }^{2}$ \\ Claudia Galdames, ${ }^{3}$ and Maria Carmen Perez-Camino ${ }^{4}$ \\ ${ }^{1}$ Departamento de Ciencias Básicas, Facultad de Ciencias, Universidad Santo Tomás, Avda. Carlos Schorr 255, 3473620 Talca, Chile \\ ${ }^{2}$ Facultad de Ciencias de la Salud, Universidad Santo Tomás, Avda. Carlos Schorr 255, 3473620 Talca, Chile \\ ${ }^{3}$ Centro de Responsabilidad Aplicación Terapéutica, Hospital Regional de Talca, 3460372 Talca, Chile \\ ${ }^{4}$ Instituto de la Grasa, 41013 Sevilla, Spain \\ Correspondence should be addressed to Marcos Flores; marcosflores@santotomas.cl
}

Received 20 December 2017; Revised 15 March 2018; Accepted 28 March 2018; Published 6 May 2018

Academic Editor: Egidio De Benedetto

Copyright (C) 2018 Marcos Flores et al. This is an open access article distributed under the Creative Commons Attribution License, which permits unrestricted use, distribution, and reproduction in any medium, provided the original work is properly cited.

\begin{abstract}
Deep-fried foods sold by unlicensed street vendors are a health concern for various reasons, but oil quality is particularly important considering known links between fat consumption and cardiovascular disease. To diagnose the exact gravity of this situation in Chile, a country where street vendors are proliferate, the physicochemical parameters of fat fractions from fried food samples were assessed. Fat quality was assessed through the acidity index, peroxide index, extinction coefficient, TOTOX index, polar compounds percentage, and fatty acid profile. Most food samples (80\%) had at least a $10 \%$ fat content. Many samples also had high peroxide values (1.7-103.3 meqO2/kg) and extinction coefficients $\left(\mathrm{K}_{232}\right.$ and $\left.\mathrm{K}_{270}\right)$, findings indicative of advanced oil deterioration. These results were supported by values for para-anisidine (100.2-311.0), TOTOX (>103.6), and polar compounds (14.2-49.7\%). All assessed food samples contained saturated, monounsaturated, and polyunsaturated fatty acids, as well as trans-fatty acids (0.6-1.7\%). According to national regulations on polar compounds, $50 \%$ of the assessed food samples are unfit for human consumption. When applying national limits for $\mathrm{C} 18$, all food samples should be discarded. These findings stress the urgent need to strictly control deep-fried foods sold by street vendors.
\end{abstract}

\section{Introduction}

Deep-fried foods are one of the most popular and longstanding culinary techniques in the world [1]. Deep frying consists of submerging foods in a high-temperature fatty medium, normally oil, until cooked to the desired taste and texture. Through this process, foods absorb a notable amount of fat and, consequently, accumulate a certain proportion of degraded products from the fatty medium [2]. Frying occurs at high temperatures and in the presence of air, moisture, and the food itself; these conditions mean that the fats/oils used for frying are subject to various alterations, such as hydrolysis and thermooxidation. The process of frying also results in the degradation of numerous compounds, including free fatty acids, hydroperoxides, monoacylglycerides, diacylglycerides, cyclic/geometric isomers of unsaturated fatty acids, and of oxidized triacylglyceride monomers, dimers, and oligomers
[3]. Noteworthy among these compounds are hydroperoxides, which are highly unstable during the frying process, form at the beginning of the deterioration process, and can degrade into secondary oxidation products [4].

Vegetable oils thermooxidize during the complex frying process in the presence of certain foods. Some compounds produced through the deterioration processes triggered by frying are likely human carcinogens. Examples of such compounds include polycyclic aromatic hydrocarbons, alkyl furans, and acrylamide [5-7]. In addition to chemical changes, oils also undergo physical modifications during frying; for example, frying potato oxidizes and browns the oil [8]. Oil quality can also further compound issues related to chemical changes and health impacts. Most oils used in industrial frying processes contain trans-fatty acids, which are primarily formed through the hydrogenation of vegetable or marine oils. The aim of hydrogenation is to 
TABLE 1: Commonly consumed fried foods were collected from seven popular street vendors in Talca, Chile. Triplicate samples of each food item were collected. Shown are the assigned codes and availability of each food item across the sampled street vendors.

\begin{tabular}{lcccccc}
\hline Street vendor & French fries & Spring rolls & Sopaipillas & Cheese empanadas & Vegetarian empanadas & Churros \\
\hline 1 & A1 & A3 & - & - & - \\
2 & A2 & - & A4 & - & - \\
3 & - & B3 & B1 & B2 & B4 & - \\
4 & - & - & - & - & - \\
5 & - & - & D1 & - & - & C1 \\
6 & - & - & E1 & E2 & D2 \\
7 & - & & - & - & - \\
\hline
\end{tabular}

improve oil resistance against thermooxidative deterioration, but the consequent trans-fatty acids negatively affect health and are specifically linked to cardiovascular diseases [9].

Worth noting, different chemical reactions have been reported for oils when exposed to high temperatures versus when used in deep frying. The products resulting from these chemical reactions would, therefore, also differ. For example, Fritsch et al. (1981) observed that some oxidation parameters in oils varied when heating only the oil versus when using the oil for deep frying $[4,10]$. The available literature widely describes the health impacts of consuming fats/oils that have been used in deep-frying processes. Indeed, the chemical traits of deep-fried oils have been largely described, providing insights into fatty acid composition and on minor constituents intentionally added to improve yields. Studies have also assessed how oil traits vary when exposed to different frying conditions [11-14]. A recent study, for example, compared the pre- versus postusage quality of frying oils in restaurants [15]. Despite these different approaches, little investigation has been conducted on situations in which deep-frying processes are poorly controlled/supervised, such as what occurs with unlicensed street vendors.

The eating habits and health of the Chilean population have changed in recent decades due to significant socioeconomic, cultural, and political changes. Consequently, a large percentage of Chile's population is currently obese or overweight [16], and while efforts have been made to curb the amount of food consumed, initiatives addressing food quality have been lacking. Chile currently ranks highest among Latin American countries in the consumption of processed foods. Fast foods and sugary drinks are widely available in Chile but offer little nutritional value and are high in calories [17]. The consumption of fast food provided by street vendors has also increased in recent years. Despite this rise in consumption, little attention has been given to evaluating food quality. This investigative gap is particularly concerning since most street food is deep-fried. In addition to established risks for cardiovascular disease (a leading cause of death in Chile), the deep-frying processes used by street vendors regularly do not adhere to sanitary protocols. Quality control measures are widely lacking, specifically as related to the shelf life, storage, and reuse of oil; disposal of discarded oil; continuous versus batch processes; frying temperature; fryer material; food type; and oil type, among other variables. Furthermore, street vendors often fry foods in open-air environments, raising concerns of other contaminants, such as vehicle pollution.

The urgency to assess oil quality is accented by the fact that high school and university students are the primary consumers of fried foods sold by street vendors, and initiatives to modify the eating habits of this age group are needed before long-lasting health consequences arise. Therefore, the main objective of this study was to evaluate the quality of oils used by street vendors in deepfrying processes. The physiochemical traits of lipid fractions present in fried foods were evaluated to establish oil quality.

\section{Materials and Methods}

2.1. Behaviour Questionnaire and Food Sampling. Prior to collecting food samples from street vendors located in Talca, Chile, a questionnaire was administered to 264 students attending the Universidad Santo Tomás, Talca Campus (12.8\% of student population). Questionnaire results were used to define the most-consumed types of deep-fried foods and the most popular street vendors from which these food products were purchased. Eight food items were named by students, six of which were available from at least one street vendor at the time of sampling. The sampled fried foods were French fries, cheese empanadas, vegetarian empanadas, spring rolls, sopapillas, and churros. Seven street vendors were included in the study, many of whom sold various types of fried foods. Triplicate samples of each food item offered by each food vendor were collected. After purchase, the food samples were immediately stored at $-18^{\circ} \mathrm{C}$ until analyses. The collected food samples and corresponding street vendors of each are shown in Table 1.

2.2. Extraction of Lipid Fractions from Fried Foods. Lipid fractions were obtained from the collected fried foods using Soxhlet methods and following conditions proposed by Marcano et al. [2], with minor modifications. Briefly, the "dough envelops" of fried foods with fillings (i.e., both empanadas, churros, and spring rolls) were removed using latex gloves. The collected dough was then shredded and homogenized using a mortar. Unfilled foods (i.e., French fries and sopaipillas) were immediately shredded and homogenized without preprocessing. All samples were dried in a forced-airstream stove for $4 \mathrm{~h}$ at $80^{\circ} \mathrm{C}$. 
Dry sample material $(\approx 120 \pm 0.1 \mathrm{~g})$ was weighed in a cellulose cone. In parallel, the weight of a flask $(2 \mathrm{~L})$ with boiling beads was recorded (3). The cellulose cone (with the dry sample material) was installed in the Soxhlet extractor $(1 \mathrm{~L})$ and connected to a flask $(2 \mathrm{~L})$ containing petroleum ether $35 / 60$. At least three rounds of extraction were conducted to obtain sufficient oil quantities for subsequent assays. After extraction, a Rotavapor rotary evaporator was used to remove solvent residues in each sample, with flasks kept at $100^{\circ} \mathrm{C}$ for $30 \mathrm{~min}$. The fat percentage of each fried food sample was calculated from the initial sample weight and the final fat content within the flask. This procedure was repeated as needed for each sample until enough oil was collected for triplicate analyses.

2.3. Chemical Analyses. The fatty acid composition of the extracted fat/oil samples was determined using a gas chromatograph (Model 5890 Series II, Hewlett Packard) equipped with a split/splitless injector with an autosampler and flameionization detector. Data were acquired using a computerized chroncard system. Samples were prepared for injection by deriving fatty acids from methyl esters using methanolic potassium $(2 \mathrm{~N})$. A SP2380 capillary column $(30 \mathrm{~m}$ long, $0.25 \mathrm{~mm}$ internal diameter, and $0.20 \mu \mathrm{m}$ film thickness) was adapted to the system. The carrier gas was hydrogen $(1 \mathrm{~mL} / \mathrm{min}$ flow rate). The injector and detector temperatures were maintained at $220^{\circ} \mathrm{C}$ and $250^{\circ} \mathrm{C}$, respectively. The initial oven temperature was $180^{\circ} \mathrm{C}$, and the applied temperature gradient ranged from $180^{\circ} \mathrm{C}$ to $220^{\circ} \mathrm{C}$ (at $\left.3^{\circ} \mathrm{C} / \mathrm{min}\right)$. A $1 \mu \mathrm{L}$ injection volume was used. Further methodological details are described in Ourrach et al. [18].

Parameters of oil quality (i.e., free acidity, peroxide values [PV], extinction coefficients $\left[\mathrm{K}_{232}\right.$ and $\left.\mathrm{K}_{270}\right]$, and para-anisidine values $[\mathrm{p}-\mathrm{AV}])$ were determined according to analytical methods described in European Commission Regulations. Total oxidation (TOTOX) values were calculated as follows: TOTOX $=2 \mathrm{PV}+\mathrm{p}-\mathrm{AV}$ [19]. The polar compounds percentage was determined using an electrochemical sensor (Testo 270, Testo AG, Lenzkirch, Germany). Sample results were randomly confirmed following a gravimetric weighing method proposed by Dobarganes et al. [20]. Most of the obtained results are represented as the mean \pm standard deviation of three replicates.

2.4. Reagents and Standards. All reagents were practical grade. The $p$-anisidine reagent was acquired from Merck Chile. Petroleum ether 35/60, ethyl ether, isooctane, acetic acid, soluble starch, potassium iodide, and sodium thiosulfate were acquired from Winkler Ltda. (Santiago, Chile).

\section{Results and Discussion}

Results from the administered questionnaire revealed students most preferred, in descending order, French fries, empanadas, spring rolls, sopaipillas, calzones rotos, churros, donuts, and Berlines (Figure 1). Over $90 \%$ of the surveyed students consumed at least one of these fried food items each month (Figure 2). This consumption frequency is concerning when taken together with the generally poor eating habits

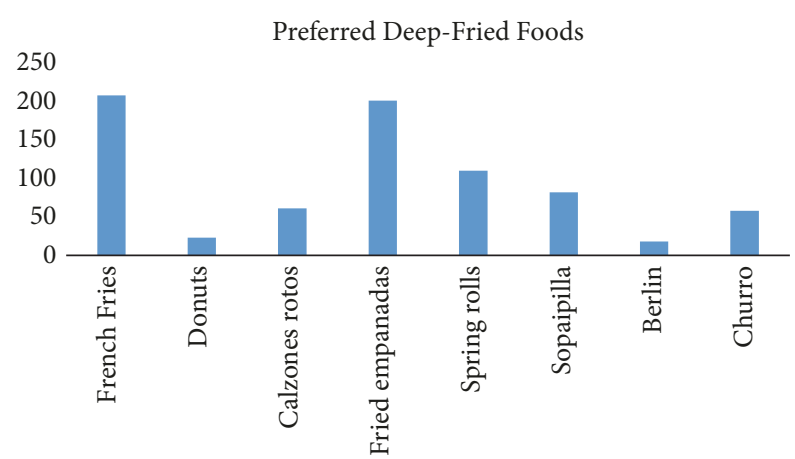

FIGURE 1: Student-declared preferences for deep-fried foods sold by local street vendors. Calzones rotos and Berlines (both typical Chilean pastries) were not sold by any street vendor when samples were collected.

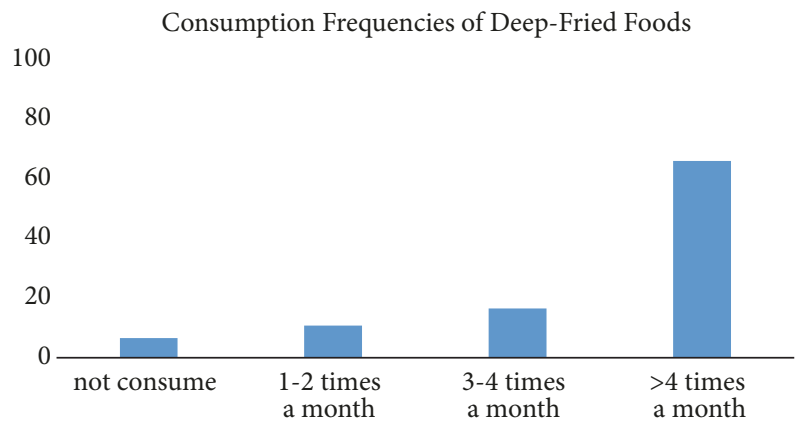

FIGURE 2: Declared consumption frequencies (\%) for deep-fried food sold by local street vendors. Four categories were established: no consumption; 1-2 times per month; 3-4 times per month; and $>4$ times per month.

of Chilean university students, that is, skipping breakfast, not always eating lunch, and poor vegetable, fruit, and dairy intake [21]. Students may be replacing healthy foods with the easily prepared, easily acquired fried foods provided by street vendors. Of the eight food items cited by students, six were included in analyses due to limitations of availability at the seven sampled street vendors (Table 1).

Regarding preferences for any particular provider, Street Vendor No. 3 was most preferred, a result likely due to being closest in proximity to the university campus (Figure 3 ). As supported by the questionnaire results, ease-of-access (i.e., saved time, less transport) was a notable factor in establishing preference for any given street vendor.

Results from the conducted physicochemical analyses are shown in Table 2. The fat percentage of the assessed samples ranged from $5.9 \%$ to $32.1 \%$. The food items with the highest fat contents $(>20 \%)$ were French fries, cheese empanadas, sopaipillas, and churros. This finding confirms the high calorie/energy contents of these food items. In contrast, the vegetable empanada had a $9.4 \%$ fat percentage. Interestingly, the two most fat-dense food items (i.e., French fries and cheese empanadas) were also the foods most preferred by students. The greater palatability of these food items likely explains the preferences indicated by students, even despite greater associated risks for an unhealthy lifestyle. 
TABLE 2: Physicochemical traits of lipid fractions collected from deep-fried food samples (see Table 1 for reference of sample coding).

\begin{tabular}{|c|c|c|c|c|c|c|c|c|}
\hline Sample & $\begin{array}{c}\text { Oil content } \\
(\%)\end{array}$ & $\begin{array}{c}\text { Polar } \\
\text { compounds } \\
(\%)\end{array}$ & Free fatty acids $\left({ }^{\circ}\right)$ & $\begin{array}{l}\text { Peroxide value } \\
\left(\text { meq }_{2} / \mathrm{kg}\right)\end{array}$ & $\mathrm{K}_{232}$ & $\mathrm{~K}_{270}$ & $p$-Anisidine & TOTOX \\
\hline $\mathrm{A} 1$ & $24.3 \pm 0.1$ & $41.2 \pm 1.2$ & $0.53 \pm 0.03$ & $103.3 \pm 0.4$ & $10.3 \pm 0.1$ & $35.99 \pm 0.03$ & $159.5 \pm 1.2$ & 366.1 \\
\hline $\mathrm{A} 2$ & $32.1 \pm 0.2$ & $20.7 \pm 0.3$ & $0.79 \pm 0.01$ & $68.5 \pm 0.2$ & $10.3 \pm 0.1$ & $36.02 \pm 0.08$ & $258.0 \pm 3.8$ & 395.0 \\
\hline A3 & $12.7 \pm 0.1$ & $30.3 \pm 0.3$ & $0.47 \pm 0.03$ & $16.9 \pm 0.2$ & $9.5 \pm 0.1$ & $55.42 \pm 0.14$ & $138.5 \pm 0.8$ & 172.3 \\
\hline A4 & $6.1 \pm 0.2$ & $19.8 \pm 0.3$ & $1.05 \pm 0.02$ & $24.4 \pm 0.9$ & $9.6 \pm 0.4$ & $37.43 \pm 0.06$ & $254.2 \pm 3.6$ & 303.0 \\
\hline B1 & $21.4 \pm 0.1$ & $29.0 \pm 0.5$ & $0.51 \pm 0.03$ & $30.1 \pm 0.7$ & $9.7 \pm 0.2$ & $21.16 \pm 0.03$ & $141.8 \pm 3.2$ & 202 \\
\hline B2 & $22.3 \pm 0.1$ & $14.2 \pm 0.3$ & $0.38 \pm 0.03$ & $42.2 \pm 0.2$ & $9.6 \pm 0.1$ & $19.76 \pm 0.03$ & $116.0 \pm 2.8$ & 200.4 \\
\hline B3 & $10.7 \pm 0.1$ & $18.7 \pm 0.2$ & $0.58 \pm 0.02$ & $63.5 \pm 1.1$ & $6.5 \pm 0.3$ & $27.54 \pm 0.04$ & $147.3 \pm 1.5$ & 274.3 \\
\hline B4 & $9.4 \pm 0.1$ & $17.2 \pm 0.3$ & $0.61 \pm 0.02$ & $19.2 \pm 0.9$ & $10.2 \pm 0.4$ & $31.28 \pm 0.03$ & $180.8 \pm 3.0$ & 219.2 \\
\hline $\mathrm{C} 1$ & $25.0 \pm 0.1$ & $21.2 \pm 0.3$ & $1.48 \pm 0.05$ & $47.7 \pm 0.7$ & $8.51 \pm 0.26$ & $39.03 \pm 0.14$ & $194.0 \pm 1.7$ & 289.4 \\
\hline D1 & $10.2 \pm 0.1$ & $31.8 \pm 0.3$ & $0.53 \pm 0.01$ & $8.1 \pm 0.6$ & $9.88 \pm 0.21$ & $32.20 \pm 0.03$ & $309.1 \pm 4.1$ & 325.3 \\
\hline D2 & $10.7 \pm 0.2$ & $49.7 \pm 0.8$ & $0.65 \pm 0.02$ & $21.4 \pm 0.1$ & $9.18 \pm 0.50$ & $39.20 \pm 0.07$ & $311.0 \pm 3.7$ & 353.8 \\
\hline D3 & $10.5 \pm 0.2$ & $24.3 \pm 0.2$ & $0.82 \pm 0.02$ & $22.6 \pm 0.2$ & $10.30 \pm 0.26$ & $34.66 \pm 0.03$ & $194.8 \pm 2.3$ & 240 \\
\hline E1 & $17.7 \pm 0.1$ & $29.2 \pm 0.3$ & $0.67 \pm 0.04$ & $1.7 \pm 0.3$ & $8.05 \pm 0.26$ & $21.10 \pm 0.03$ & $100.2 \pm 1.4$ & 103.6 \\
\hline E2 & $22.4 \pm 0.2$ & $41.3 \pm 1.0$ & $0.71 \pm 0.01$ & $3.7 \pm 0.3$ & $10.29 \pm 0.35$ & $25.22 \pm 0.08$ & $122.7 \pm 0.9$ & 130.1 \\
\hline
\end{tabular}

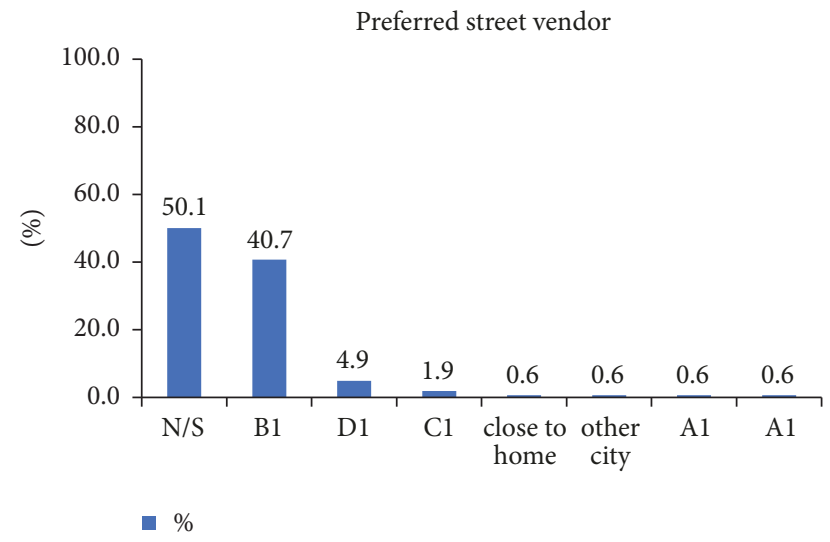

FIGURE 3: Declared preference (\%) for purchasing a specific deepfried food item at a particular street vendor. N/S, no preference.

Most international regulations regarding the quality of frying oils cite limits for the acidity index and polar compounds percentage [22]. In Chile, the established limits for refined oils used in frying processes are $2.5 \%$ for acidity and $25 \%$ for polar compounds [23]. The currently assessed samples did not exceed the regulated acidity value. Nevertheless, unused refined oils should not have a free fatty acids content greater than $0.1 \%$, specifically since free fatty acids are removed during the industrial refining process [15]. The average free fatty acids content of the evaluated food samples ranged from $0.38 \%$ to $1.48 \%$, values indicative of a hydrolytic degradation of triacylglycerides. Since hydrolytic degradation in frying processes is related to the release of water in food towards triacylglycerides in the fatty medium, acidity would be conditioned by the humidity of each food item and by the processing conditions of the frying oil. While the obtained acidity values did not exceed established regulations, the frying processes of street vendors are poorly controlled. Frying oil is infrequently discarded, with vendors instead simply adding more as oil is absorbed by the frying food. This practice would decrease the rate of hydrolytic alterations and, therefore, mask or slow down this type of deterioration. Controlled frying processes (e.g., those for mass-produced snack foods) present acidity index values between $0.25 \%$ and $0.40 \%$. Furthermore, Tseng et al. [24] suggest that frying oils be discarded when acidity exceeds $1 \%$. If this limit was applied to the presently assessed food items, $14 \%$ of the sample group should be discarded. Regarding polar compounds, $50 \%$ of the studied samples exceeded currently established limits. The most extreme case presented a polar compound percentage of $49 \%$. In most cases, this indicator is the most reliable for determining fat/oils deterioration since both hydrolytic and oxidative degradation are considered [4].

Peroxides, primary oxidation products, are the most commonly used parameter to evaluate oxidation in fats. However, these compounds change into secondary oxidation products, and, consequently, peroxides should not be the only parameter used in measuring the oxidative state of a fat. Prior research indicates that peroxides rapidly degrade in high-temperature oils, such as during frying processes. However, high values of this parameter can occur as a result of oxidation processes in cooled, fried foods. These effects of temperature are very important to consider since the frying and postfrying processes of street vendors are largely uncontrolled [25]. Sulieman et al. [26] stated that a goodquality vegetable oil for frying should have a peroxide index of $<2$ meq O2/kg [26]. Chilean legislation does not regulate this parameter for frying oils, but European regulations indicate $10 \mathrm{meq} \mathrm{O} / \mathrm{kg}$ as a maximum for vegetable oils [27]. The analysed samples presented a wide range of peroxide values, going from 1.7 meq $\mathrm{O} 2 / \mathrm{kg}$ to $103.3 \mathrm{meq} \mathrm{O} 2 / \mathrm{kg}$. When applying the criterion proposed by Sulieman et al. [26], 92\% of the evaluated samples would be classified as poor-quality. 
Furthermore, only 3 of 14 samples had a peroxide limit < $10 \mathrm{meq} \mathrm{O} / \mathrm{kg}$. Considering both of these criteria, most of the assessed food samples were highly oxidized.

Absorbance measurements at $232 \mathrm{~nm}\left(\mathrm{~K}_{232}\right)$ and $272 \mathrm{~nm}$ $\left(\mathrm{K}_{272}\right)$ are used to determine fat oxidation, with parameter values varying depending on oxidation conditions. $\mathrm{K}_{232}$ is associated with the generation of primary oxidation products (i.e., conjugated dienes) [27], and there is an excellent correlation of this parameter with the peroxide index when unsaturated vegetable oils are undergoing oxidation [28]. According to Marmesat et al. [28], $\mathrm{K}_{232}$ values $>4$ correlate with unacceptable peroxide index values (i.e., $<10$ meq $\mathrm{O} 2 / \mathrm{kg}$ in Europe). In the current study, all $\mathrm{K}_{232}$ values were $>6$. Taken together with the aforementioned peroxide values, the evaluated deep-fried food samples would be in an advanced state of oxidation. In turn, $\mathrm{K}_{270}$ is associated with the generation of conjugated trienes. According to López-Varela et al. [29], $K_{270}$ values increase in frying vegetable oils, and after 30 frying cycles, $K_{270}$ values exceeded the 7-unit limit [29]. All of the currently evaluated food samples far exceeded this 7-unit limit for $\mathrm{K}_{270}$, thus confirming an advanced state of oxidation.

Hydroperoxides are highly unstable compounds that rapidly decompose to form secondary oxidation products via cleavage of the $\mathrm{C}-\mathrm{C}$ bond. These secondary oxidation products include aldehydes, alcohols, and ketones. ParaAnisidine values are a measure of aldehyde content in oils, mainly 2,4-dienal and 2-alkenyl oils [30]. This index has been rated as the most reliable for determining fat/oil oxidation as it measures the accumulation of secondary oxidation compounds, components that are more stable than hydroperoxides [31]. According to the literature, good-quality oils should have $p$-anisidine values $<10$ [32]. Index values for the present study ranged from 100.2 to 309.1. Sebastian et al. [15] reported a maximum $p$-anisidine value of 56.5 for discarded oil from a restaurant in Canada. In turn, AlKahtani [31] reported a maximum value of 147.6 for frying oils from established restaurants. All of the currently assessed samples exceed the $p$-anisidine value given by Sebastian et al. [15], while $57 \%$ exceed the value cited by Al-Kahtani [31]. The determined $p$-anisidine values are of particular concern since measurements were directly obtained from food to be consumed and not from oil in the frying medium.

The TOTOX index is a good indicator for the total deterioration of fats and oils. This index relates the peroxide index to the $p$-anisidine index, providing a reading of primary and secondary oxidation products [33]. Furthermore, the TOTOX index is highly correlated to other oxidation measures for vegetable oils subjected to oxidation processes [34]. Subramanian et al. [35] proposed that good-quality vegetable oils have TOTOX values $<4$. In the present study, $100 \%$ of the assessed samples extremely exceeded this limit (103.6-395.0), thus further supporting the high oxidation status of the evaluated fried fats.

The fatty acid composition was also determined for each of the assessed fried food samples (Table 3). Fatty acid composition varied among all samples, but each presented saturated, monounsaturated, and polyunsaturated fatty acids, with cis and trans configurations. Saturated fatty acids accounted for $13.9 \%$ to $26.5 \%$ of the total fatty acid composition, while monounsaturated fats accounted for $23.2 \%$ to $33.5 \%$, and polyunsaturated fats accounted for $45.5 \%$ to $59.3 \%$. Oil yields in frying processes heavily depend on the fatty acid composition. Polyunsaturated fatty acids, such as linoleic and linolenic, are the components mainly affected by several chemical reactions that occur when frying vegetable oils. These reactions ultimately reduce the presence of polyunsaturated fatty acids and increase concentrations of saturated fatty acids $[26,36]$. The improved stability of oils to frying after hydrogenation is due to a decrease in polyunsaturated fatty acids such as linolenic; however, hydrogenation is related to the generation of trans-fatty acids, which are negatively associated with human health [37].

The polyunsaturated-to-saturated fatty acid ratio, termed the polyene index, measures the degree to which an oil is polyunsaturated and the tendency of the oil to undergo autoxidation [19]. For the studied samples, polyene index values ranged from 1.72 to 3.78 . Ma et al. [38] reported that values of this index decrease when vegetable oils are subjected to prolonged frying processes, with or without a replacement of fresh oils. Furthermore, fresh vegetable oils present a polyene index $>4$ whereas, following the deterioration process of frying, the polyene index is $<4$ [38]. Samples from the present study all had polyene values $<4$, representing an advanced stage of deterioration.

In addition to the polyene index, the ratio of linoleicto-palmitic fatty acids (i.e., C18:2-to-C16:0) can serve as a reliable indicator of deterioration degree in polyunsaturated fatty acids [31]. Aladedunye and Przybylski [8] reported that values of indicator decrease to $<4.37$ when canola oil is subjected to different frying processes [8]. The present samples evidenced a C18:2-to-C16:0 range from 2.64 to 5.89, with $71 \%$ having values $<4.37$. The observed variability can be partially attributed to the addition of fresh oil during the frying process and partially to the lack of control in the type of food fried. More specifically, the evaluated food products may have fats leached to the frying medium, which would change the composition of fatty acids. Current Chilean regulations on oil/shortening usage in industrial or commercial frying processes state that C18:3 fatty acid contents should not exceed 2\% [23]. This limit was established to prevent high oxidation levels when frying, specifically since C18:3 is polyunsaturated and, therefore, highly prone to oxidation. While the assessed oil samples were obtained from different foods and not directly from the frying medium, C18:3 levels still exceed the established $2 \%$ limit. This finding stresses the need for more potent enforcement measures of existing regulations, specifically as associated with the quality and composition of oils used for frying food goods destined for human consumption.

Deep frying is a likely source of trans-fatty acids [39]. These fatty acids have been investigated in hydrogenated and nonhydrogenated vegetable oils-increasing when oils are subjected to frying or heating processes $[8,39]$. Transfatty acid intake, particularly in high amounts, is linked to systemic inflammation, coronary disease, diabetes, and breast cancer [40-42]. These associations have led several countries to strictly regulate the presence and/or total content 
TABLE 3: Composition (\%) of fatty acids in lipid fractions obtained from deep-fried food samples (see Table 1 for reference of sample coding).

\begin{tabular}{|c|c|c|c|c|c|c|c|c|c|c|c|c|c|c|}
\hline \multirow{2}{*}{ Fatty acid } & \multicolumn{14}{|c|}{ Sample } \\
\hline & $\mathrm{A} 1$ & $\mathrm{~A} 2$ & A3 & A4 & $\mathrm{B} 1$ & B2 & B3 & B4 & $\mathrm{C} 1$ & D1 & D2 & D3 & E1 & E2 \\
\hline C14:0 & - & - & - & - & 1.3 & 0.4 & 0.1 & 0.2 & 0.1 & 0.6 & 0.1 & 0.1 & 0.3 & 0.5 \\
\hline $\mathrm{C} 16: 0$ & 12.3 & 11.9 & 12.4 & 11.9 & 14.0 & 13.4 & 11.4 & 11.5 & 8.4 & 15.4 & 12.2 & 11.3 & 16.9 & 16.0 \\
\hline C16:1 & 0.2 & - & 0.1 & 0.1 & 0.5 & 0.4 & 0.1 & 0.1 & 0.1 & 0.7 & 0.2 & 0.1 & 0.1 & 0.5 \\
\hline C18:0 & 5.2 & 5.1 & 5.3 & 4.9 & 6.5 & 7.2 & 5.2 & 5.3 & 4.2 & 9.7 & 5.2 & 4.9 & 5.0 & 8.3 \\
\hline trans-C18:1 & - & - & - & - & 0.4 & 0.2 & - & - & - & 0.5 & - & - & - & - \\
\hline cis-C18:1 & 24.3 & 23.2 & 24.3 & 23.1 & 25.4 & 26.1 & 23.9 & 24.4 & 33.2 & 26.6 & 23.9 & 23.3 & 25.1 & 25.5 \\
\hline trans-C18:2 & 0.6 & 0.6 & 0.6 & 0.6 & 0.2 & 0.2 & 0.2 & 0.2 & 0.4 & 0.3 & 0.4 & 0.3 & 0.4 & 0.3 \\
\hline cis-C18:2 & 50.5 & 51.8 & 50.0 & 51.0 & 45.1 & 45.4 & 51.6 & 51.1 & 49.1 & 40.3 & 50.6 & 52.1 & 44.8 & 42.0 \\
\hline C20:0 & 0.5 & 0.5 & 0.5 & 0.5 & 0.4 & 0.4 & 0.4 & 0.4 & 0.4 & 0.4 & 0.4 & 0.4 & 0.4 & 0.4 \\
\hline trans-C18:3 & 0.5 & 0.6 & 0.8 & 1.1 & 0.4 & 0.4 & 0.5 & 0.4 & 0.4 & 0.6 & 0.7 & 0.7 & 0.9 & 0.8 \\
\hline cis-C18:3 & 5.7 & 6.3 & 5.3 & 6.0 & 5.2 & 5.2 & 5.9 & 5.7 & 2.7 & 4.3 & 5.6 & 6.1 & 5.4 & 5.0 \\
\hline C20:1 & 0.2 & - & 0.2 & 0.2 & 0.2 & 0.3 & 0.2 & 0.2 & 0.2 & 0.2 & 0.2 & 0.2 & 0.2 & 0.3 \\
\hline C22:0 & - & - & 0.4 & 0.4 & 0.3 & 0.3 & 0.4 & 0.4 & 0.6 & 0.3 & 0.4 & 0.4 & 0.4 & 0.3 \\
\hline $\mathrm{C} 24: 0$ & - & - & 0.1 & 0.2 & 0.1 & 0.1 & 0.1 & 0.1 & 0.2 & 0.1 & 0.1 & 0.1 & 0.1 & 0.1 \\
\hline SFA & 18.0 & 17.5 & 18.7 & 17.9 & 22.6 & 21.8 & 17.6 & 17.9 & 13.9 & 26.5 & 18.4 & 17.2 & 23.1 & 25.6 \\
\hline MUFA & 24.7 & 23.2 & 24.6 & 23.4 & 26.5 & 27.0 & 24.2 & 24.7 & 33.5 & 28.0 & 24.3 & 23.6 & 25.4 & 26.3 \\
\hline PUFA & 57.3 & 59.3 & 56.7 & 58.7 & 50.9 & 51.2 & 58.2 & 57.4 & 52.6 & 45.5 & 57.3 & 59.2 & 51.5 & 48.1 \\
\hline $\mathrm{P} / \mathrm{S}$ & 3.18 & 3.39 & 3.03 & 3.28 & 2.25 & 2.35 & 3.31 & 3.21 & 3.78 & 1.72 & 3.11 & 3.44 & 2.23 & 1.88 \\
\hline $\mathrm{M} / \mathrm{P}$ & 0.43 & 0.39 & 0.43 & 0.40 & 0.52 & 0.53 & 0.42 & 0.43 & 0.64 & 0.62 & 0.42 & 0.40 & 0.49 & 0.55 \\
\hline Total TFAs & 1.1 & 1.2 & 1.4 & 1.7 & 1.0 & 0.8 & 0.7 & 0.6 & 0.8 & 1.4 & 1.1 & 1.0 & 1.3 & 1.1 \\
\hline C18:2/C16:0 & 4.15 & 4.40 & 4.08 & 4.34 & 3.24 & 3.39 & 4.54 & 2.64 & 5.89 & 2.64 & 4.18 & 4.64 & 2.67 & 2.64 \\
\hline
\end{tabular}

SFA, saturated fatty acids; MUFA, monounsaturated fatty acids; PUFA, polyunsaturated fatty acids; P/S, ratio of polyunsaturated fatty acids and saturated fatty acids; $\mathrm{M} / \mathrm{P}$, ratio of monounsaturated fatty acids versus polyunsaturated fatty acids; TFA, trans-fatty acids.

of trans-fatty acids in food. For example, the USA Food and Drug Administration and the Canadian Food Inspection Agency require food producers to declare trans-fatty acid contents directly on product labels $[43,44]$. In 2003, Denmark implemented a $2 \mathrm{~g}$ maximum of trans-fatty acids per $100 \mathrm{~g}$ of fat/oil destined for human consumption [45]. Spain has similarly taken measures to reduce trans-fatty acid contents in industrial food products [46]. Nevertheless, there is concern that these regulations are too focused on industrial trans-fatty acids and not on those produced naturally, such as by ruminants. Chilean regulations currently stipulate that products can be described as trans-fatty acid "free" when contents account for $<0.2 \%$, that is, a $2 \mathrm{~g}$ maximum of saturated fat per $100 \mathrm{~g}$ serving. Regulations further state that trans-fatty acids produced by industrial processes should not exceed $2 \%$ of total fat contents [23]. Despite international and local efforts to regulate trans-fatty acids, information regarding the presence and/or established contents of transfatty acid is widely lacking in relation to foods sold by unlicensed street vendors. While the currently assessed food samples did not exceed the $2 \%$ limit, trans-fatty acid contents ranged from 0.6 to $1.7 \%$.

For comparative purposes, two food samples (E1 and E2) were obtained from a licensed food establishment authorized to sell fried foods. Unfortunately, values for the different evaluated indexes were similar between the street vendors and licensed establishments. The exception to this was for the peroxide index, which for both samples from established food venues was within the acceptable range of values per existing regulations.

A primary concern approximated by the presented research is that of establishing food qualities for determined target populations. Assessments focused primarily on lipid fraction quality assessments of foods subjected to deep-frying processes. Comparative research has, as yet, focused on the distinct methods and/or conditions of the frying processes of the different street vendors, since it is not possible to access the information on the individual operating conditions of each one of them.

In this sense, the analysis and discussion of the results are based on the comparison of the obtained values with those proposed in national and international regulations and even suggestions of values obtained by other researchers for the analysed chemical-physical parameters.

\section{Conclusions}

A high proportion of university students declare themselves as a consumer of fried foods $(>90 \%)$ and a high percentage of these foods $(>85 \%)$ contain a high fat percentage $(>10 \%)$. This situation becomes a risk factor for the health of this population, since it is well known that this type of food could suffer deterioration of its fat when subjected to high temperatures and the influence of this on the increased risk of suffering cardiovascular diseases.

Parallelly, this group declares buying these foods in the itinerant street trade which adds more factors of concern 
because of the lack of sanitary and of operation control that this sale points have and the lack of regulation about those points of concern.

To assess the degree of health risk, an approximation to the evaluation of the quality of the fat present in these foods can be made through physicochemical analyses that show if there is thermooxidative deterioration derived from the cooking process to which they are subjected.

Through the study and analysis of the lipid fraction of foods subjected to deep-frying processes offered by the street trade, it is clearly demonstrated that the fat present in them is highly oxidized and hydrolysed.

According to values suggested in literature for the acidity index, $14 \%$ of the samples studied should be discarded, in addition and according to the national regulation for the percentage of polar compounds, $50 \%$ of the samples should be discarded. For the percentage for C18:3 fatty acid according to local regulation, all samples exceed the limit value $(>2 \%)$; therefore, they should be discarded from the sale process.

\section{Data Availability}

The [DATA TYPE] data used to support the findings of this study are available from the corresponding author upon request.

\section{Disclosure}

The abstract of this study was accepted for poster presentation at the 21st World Congress of Epidemiology, IEA, Tokyo, Japan.

\section{Conflicts of Interest}

The authors declare that there are no conflicts of interest regarding the publication of this paper.

\section{Acknowledgments}

Dr. Marcos Flores thanks the Research and Postgraduate Department of the Universidad Santo Tomás for the financial support to this research through the internal project [code TAS 0000015989].

\section{References}

[1] F. M. A. Rehab and A. M. E. Anany, "Physicochemical studies on sunflower oil blended with cold pressed tiger nut oil during the deep frying process," Grasas y Aceites, vol. 63, no. 4, pp. 455465, 2012.

[2] J. Marcano, Y. L. Rosa, and N. Salinas, "Influence of the deep fat frying process on the lipid profile of the fat contained in the "french" type fried potato using palm olein," Grasas y Aceites, vol. 61, no. 1, pp. 24-29, 2010.

[3] E. Tabee, M. Jägerstad, and P. C. Dutta, "Frying Quality Characteristics of French Fries Prepared in Refined Olive Oil and Palm Olein," Journal of the American Oil Chemists' Society, vol. 86, no. 9, pp. 885-893, 2009.
[4] C. W. Fritsch, "Measurements of frying fat deterioration: a brief review," Journal of the American Oil Chemists' Society, vol. 58, no. 3, pp. 272-274, 1981.

[5] G. Hu, Y. Zhu, M. Hernandez, T. Koutchma, and S. Shao, "An efficient method for the simultaneous determination of furan, 2-methylfuran and 2-pentylfuran in fruit juices by headspace solid phase microextraction and gas chromatography-flame ionisation detector," Food Chemistry, vol. 192, Article ID 17782, pp. 9-14, 2016.

[6] X. Hao, J. Li, and Z. Yao, "Changes in PAHs levels in edible oils during deep-frying process," Food Control, vol. 66, pp. 233-240, 2016.

[7] Y. Yang, I. Achaerandio, and M. Pujolà, "Influence of the frying process and potato cultivar on acrylamide formation in French fries," Food Control, vol. 62, pp. 216-223, 2016.

[8] F. A. Aladedunye and R. Przybylski, "Degradation and nutritional quality changes of oil during frying," Journal of the American Oil Chemists' Society, vol. 86, no. 2, pp. 149-156, 2009.

[9] A. Bysted, A. Æ. Mikkelsen, and T. Leth, "Substitution of trans fatty acids in foods on the Danish market," European Journal of Lipid Science and Technology, vol. 111, no. 6, pp. 574-583, 2009.

[10] D. P. Houhoula, V. Oreopoulou, and C. Tzia, "A kinetic study of oil deterioration during frying and a comparison with heating," Journal of the American Oil Chemists' Society, vol. 79, no. 2, pp. 133-137, 2002.

[11] J. S. Lioumbas and T. D. Karapantsios, "Effect of increased gravitational acceleration in potato deep-fat frying," Food Research International, vol. 55, pp. 110-118, 2014.

[12] S. Marmesat, A. Morales, J. Velasco, and M. Carmen Dobarganes, "Influence of fatty acid composition on chemical changes in blends of sunflower oils during thermoxidation and frying," Food Chemistry, vol. 135, no. 4, pp. 2333-2339, 2012.

[13] F. Aladedunye and R. Przybylski, "Frying stability of high oleic sunflower oils as affected by composition of tocopherol isomers and linoleic acid content," Food Chemistry, vol. 141, no. 3, pp. 2373-2378, 2013.

[14] J. Garayo and R. Moreira, "Vacuum frying of potato chips," Journal of Food Engineering, vol. 55, no. 2, pp. 181-191, 2002.

[15] A. Sebastian, S. M. Ghazani, and A. G. Marangoni, "Quality and safety of frying oils used in restaurants," Food Research International, vol. 64, pp. 420-423, 2014.

[16] Ministerio de Salud, Encuesta Nacional de Salud ENS Chile 2009-2010, vol. 10 of Estrategia Nacional de Salud para el cumplimiento de los Objetivos Sanitarios de la Década 2011-2020, 2011, Es Chile un país saludable.

[17] C. Cid, E. Báscolo, and C. Morales, Alimentos y Bebidas Ultraprocesados en America Latina: tendencias, efecto sobre la obesidad e implicaciones para las políticas públicas, Organización Panamericana de la Salud, Organización Mundial de la Salud, Departamento de Enfermedades no transmisibles y Salud Mental, Washington D.C., USA, 2015.

[18] I. Ourrach, M. Rada, M. C. Pérez-Camino, M. Benaissa, and Á. Guinda, "Detection of argan oil adulterated with vegetable oils: New markers," Grasas y Aceites, vol. 63, no. 4, pp. 355-364, 2012.

[19] R. Farhoosh, R. Esmaeilzadeh Kenari, and H. Poorazrang, "Frying stability of canola oil blended with palm olein, olive, and corn oils," Journal of the American Oil Chemists' Society, vol. 86, no. 1, pp. 71-76, 2009.

[20] M. C. Dobarganes, J. Velasco, and A. Dieffenbacher, "Determination of polar compounds, polymerized and oxidized triacylglycerols, and diacylglycerols in oils and fats: Results of 
collaborative studies and the standardized method (Technical report)," Pure and Applied Chemistry, vol. 72, no. 8, pp. 1563$1575,2000$.

[21] R. Ratner G, P. Hernández J, J. Martel A, and E. Atalah S, "Calidad de la alimentación y estado nutricional en estudiantes universitarios de 11 regiones de Chile," Revista Médica de Chile, vol. 140, no. 12, pp. 1571-1579, 2012.

[22] W. Chen, C. Chiu, W. Cheng, C. Hsu, and M. Kuo, “Total polar compounds and acid values of repeatedly used frying oils measured by standard and rapid methods," Journal of Food and Drug Analysis, vol. 21, no. 1, pp. 58-65, 2013.

[23] "Reglamento sanitario de los Alimentos, Decreto Supremo 977/96," Republica de Chile.

[24] Y.-C. Tseng, R. Moreira, and X. Sun, "Total frying-use time effects on soybean-oil deterioration and on tortilla chip quality," International Journal of Food Science \& Technology, vol. 31, no. 3, pp. 287-294, 1996.

[25] L. Masson, P. Robert, N. Romero et al., "Comportamiento de aceites poliinsaturados en la preparación de patatas fritas para consumo inmediato: Formación de nuevos compuestos y comparación de métodos analíticos," Grasas y Aceites, vol. 48, no. 5, pp. 273-281, 1997.

[26] A. E. L.-R. M. Sulieman, A. El-Makhzangy, and M. F. Ramadan, "Antiradical performance and physicochemical characteristics of vegetable oils upon frying of french fries: A preliminary comparative study," Journal of Food Lipids, vol. 13, no. 3, pp. 259276, 2006.

[27] S. Bozdemir, O. Güneşer, and E. Yilmaz, "Properties and stability of deep-fat fried chickpea products," Grasas y Aceites, vol. 66, no. 1, article no. e065, 2015.

[28] S. Marmesat, A. Morales, J. Velasco, M. V. Ruiz-Méndez, and M. C. Dobarganes, "Relationship between changes in peroxide value and conjugated dienes during oxidation of sunflower oils with different degree of unsaturation," Grasas y Aceites, vol. 60, no. 2, pp. 155-160, 2009.

[29] S. López-Varela, F. J. Sánchez-Muniz, C. Garrido-Polonio, R. Arroyo, and C. Cuesta, "Relationship between chemical and physical indexes and column and HPSE chromatography methods for evaluating frying oil," Zeitschrift für Ernährungswissenschaft, vol. 34, no. 4, pp. 308-313, 1995.

[30] C. Tompkins and E. G. Perkins, "Evaluation of frying oils with the p-anisidine value," Journal of the American Oil Chemists' Society, vol. 76, no. 8, pp. 945-947, 1999.

[31] H. A. Al-Kahtani, "Survey of quality of used frying oils from restaurants," Journal of the American Oil Chemists' Society, vol. 68, no. 11, pp. 857-862, 1991.

[32] Y. B. Che Man and W. R. Wan Hussin, "Comparison of the frying performance of refined, bleached and deodorized palm olein and coconut oil," Journal of Food Lipids, vol. 5, no. 3, pp. 197210, 1998.

[33] T. Shahidi and U. Wanasundara, "Methods for measuring oxidative rancidity in fats and oils," in Food lipids, chemistry, nutrition and biotechnology, C. C. Akoh and D. B. Mind, Eds., EEUU, New York, NY, USA, 2002.

[34] A. M. Rauen-Miguel, W. Esteves, and D. Barrera-Arellano, "Determinación del período de inducción de aceite de soja Correlación entre el Rancimat y otros índices," Grasas y Aceites, vol. 43, no. 3, pp. 119-122, 1992.

[35] R. Subramanian, K. E. Nandini, P. M. Sheila et al., "Membrane processing of used frying oils," Journal of the American Oil Chemists' Society, vol. 77, no. 3, pp. 323-328, 2000.
[36] K. Warner and T. L. Mounts, "Frying stability of soybean and canola oils with modified fatty acid compositions," Journal of the American Oil Chemists' Society, vol. 70, no. 10, pp. 983-988, 1993.

[37] D. A. Pereira de Abreu, P. P. Losada, J. Maroto, and J. M. Cruz, "Evaluation of the effectiveness of a new active packaging film containing natural antioxidants (from barley husks) that retard lipid damage in frozen Atlantic salmon (Salmo salar L.)," Food Research International, vol. 43, no. 5, pp. 1277-1282, 2010.

[38] J.-K. Ma, H. Zhang, T. Tsuchiya, Y. Akiyama, and J.-Y. Chen, "Frying stability of rapeseed Kizakinonatane (Brassica napus) oil in comparison with canola oil," Food Science and Technology International, vol. 21, no. 3, pp. 163-174, 2015.

[39] Y. Chen, Y. Yang, S. Nie et al., "The analysis of trans fatty acid profiles in deep frying palm oil and chicken fillets with an improved gas chromatography method," Food Control, vol. 44, pp. 191-197, 2014.

[40] D. Mozaffarian, M. B. Katan, A. Ascherio, M. J. Stampfer, and W. C. Willett, "Trans fatty acids and cardiovascular disease," The New England Journal of Medicine, vol. 354, no. 15, pp. 1601-1613, 2006.

[41] R. Micha and D. Mozaffarian, "Trans fatty acids: Effects on metabolic syndrome, heart disease and diabetes," Nature Reviews Endocrinology, vol. 5, no. 6, pp. 335-344, 2009.

[42] L. Kohlmeier, "Trans-fatty acids and breast cancer," Food and Chemical Toxicology, vol. 35, no. 12, p. 1228, 1997.

[43] Food and Drug Administration, "Guidance for industry: Trans fatty acids in nutrition labeling, nutrient content claims, health claims; small entity compliance guide," 2003, http://www.fda .gov/Food/GuidanceRegulation/GuidanceDocumentsRegulatoryInformation/LabelingNutrition/ucm053479.htm.

[44] Canadian Food Inspection Agency, "Labelling of trans fatty acids," 2017, http://www.inspection.gc.ca/english/fssa/labeti/inform/transe.shtml.

[45] "Danish Veterinary and Food Administration," Trans fatty acids content in Food, 2017, https://www.foedevarestyrelsen.dk/ english/Food/Pages/default.aspx.

[46] "Ley 17/2011, de 5 de julio, de seguridad alimentaria y nutrición," España: Boletín Oficial del Estado, vol. 160, no. 6, 2011. 


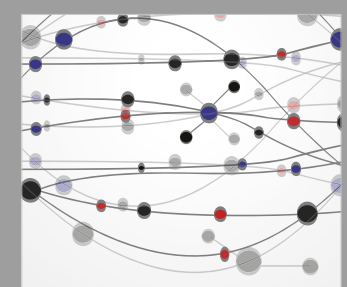

The Scientific World Journal
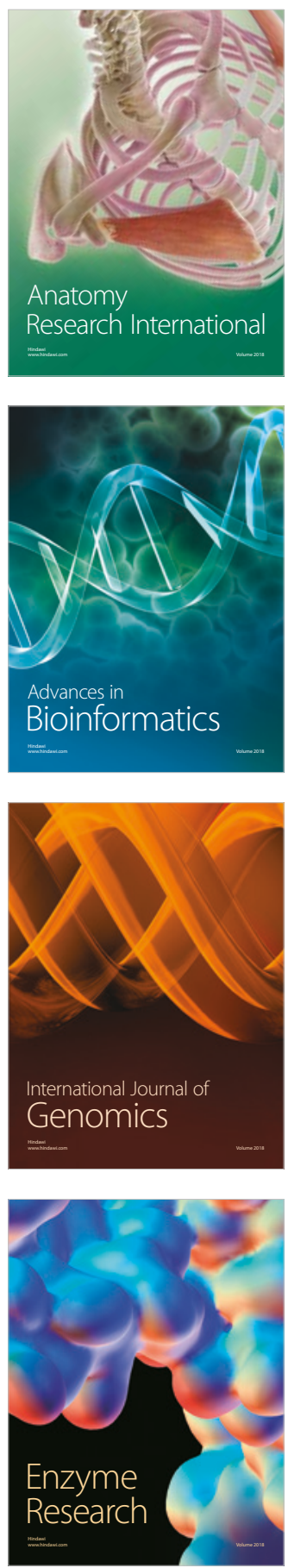
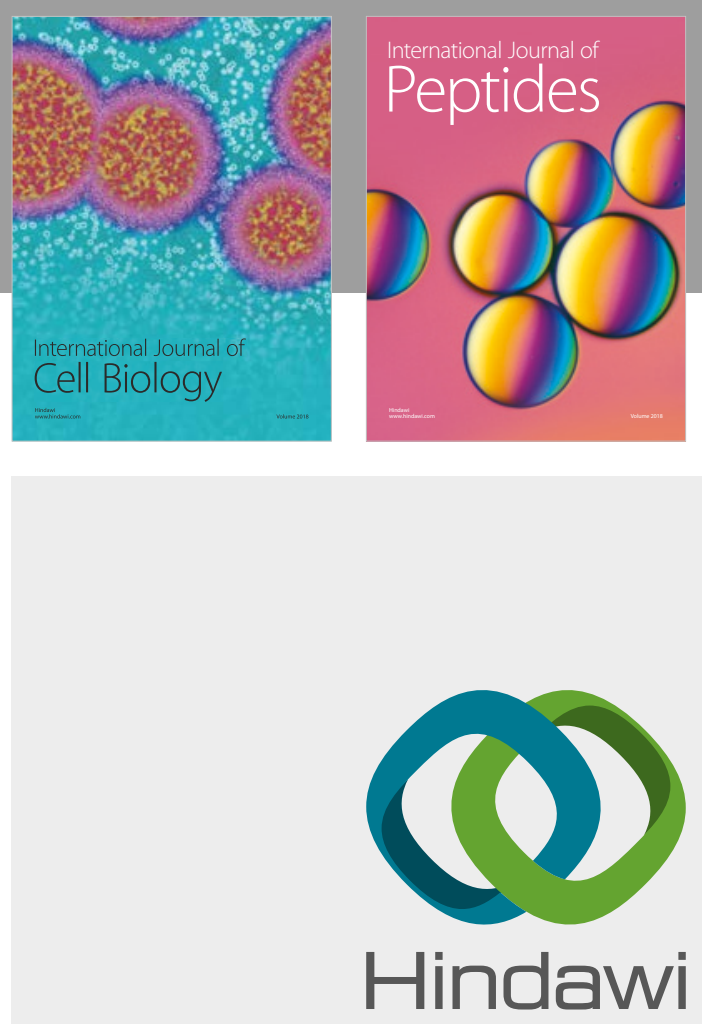

Submit your manuscripts at

www.hindawi.com
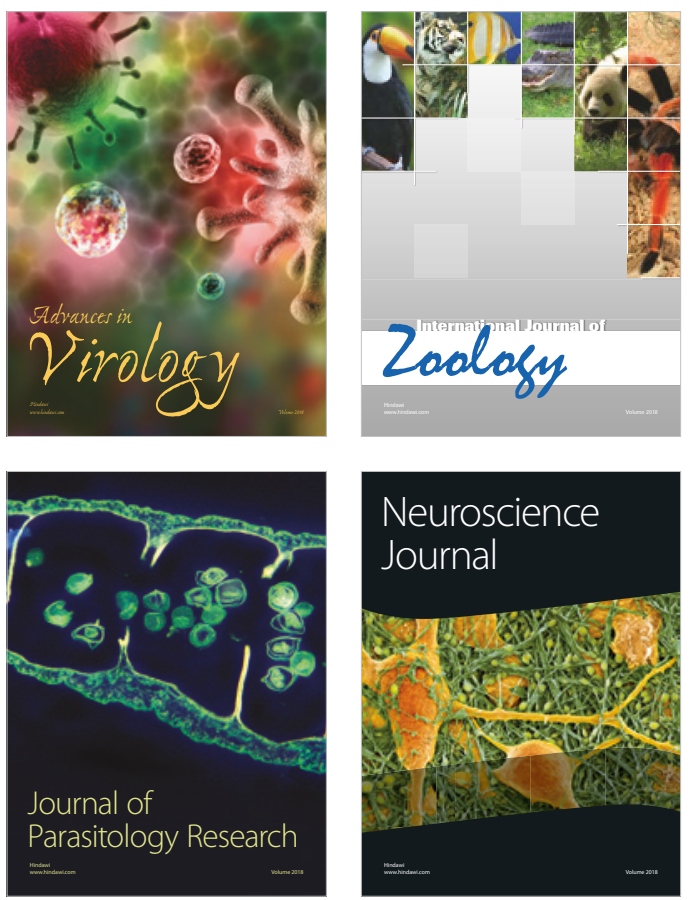
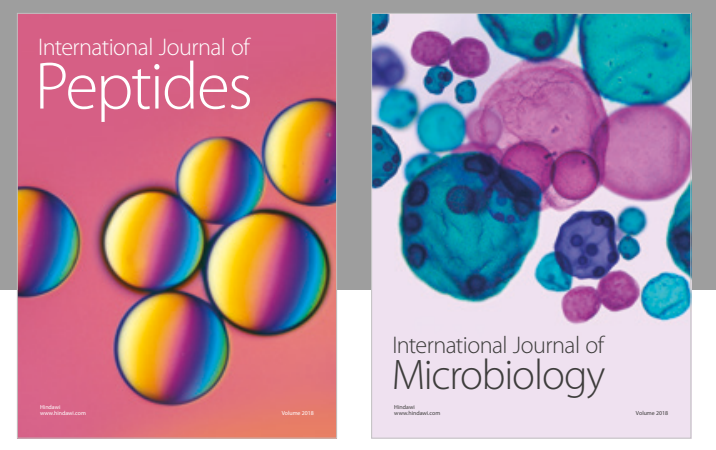

nternational Journal of Microbiology
Journal of
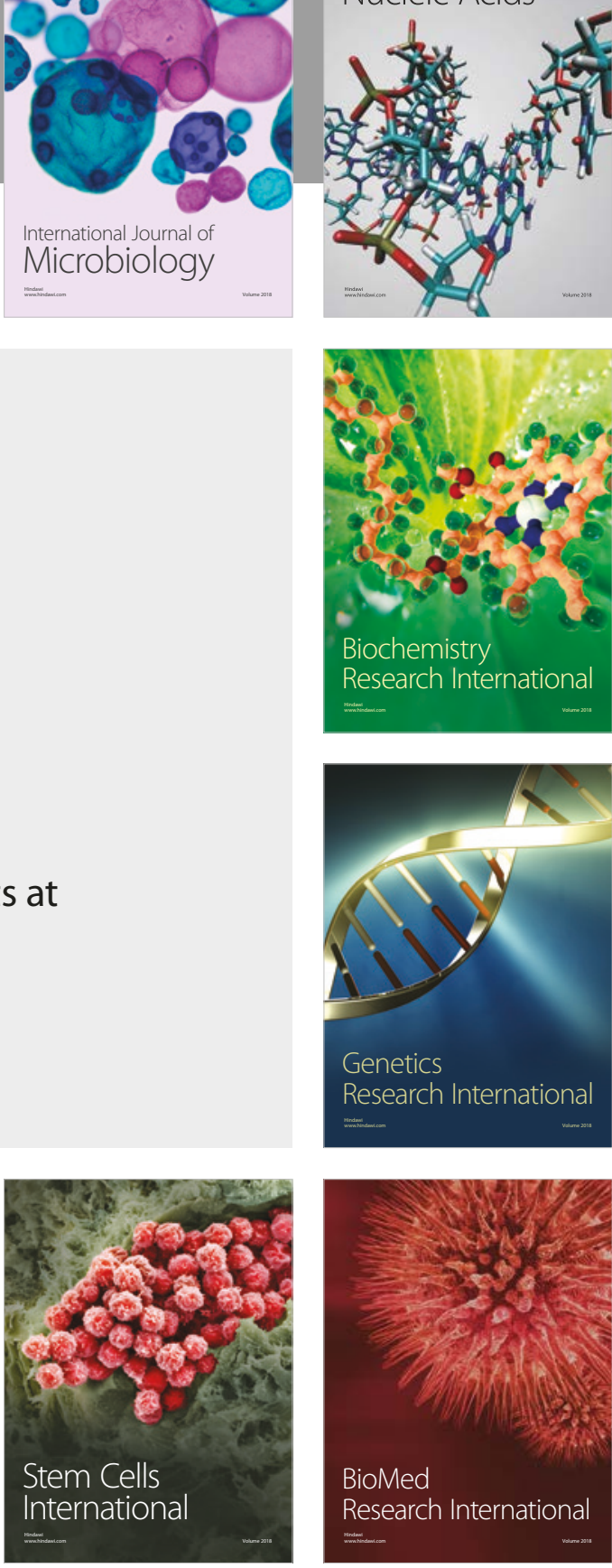
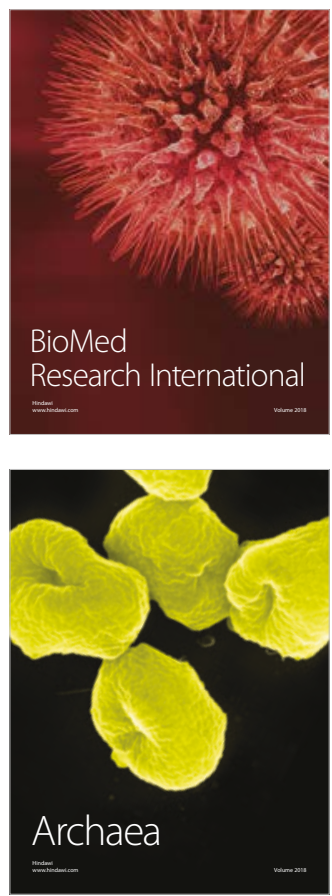